\title{
Predictive imaging for thoracic aortic dissection and rupture: moving beyond diameters
}

\author{
Bouke P. Adriaans $\mathrm{s}^{1,2,3}$ (D) Joachim E. Wildberger ${ }^{1,3} \cdot$ Jos J. M. Westenberg ${ }^{4} \cdot$ Hildo J. Lamb $^{4} \cdot$ Simon Schalla ${ }^{1,2,3}$
}

Received: 13 March 2019 / Revised: 7 May 2019 / Accepted: 11 June 2019 / Published online: 5 July 2019

(C) The Author(s) 2019

\begin{abstract}
Acute aortic syndromes comprise a group of potentially fatal conditions that result from weakening of the aortic vessel wall. Preemptive surgical intervention is currently reserved for patients with severe aortic dilatation, although abundant evidence describes the occurrence of dissection and rupture in aortas with diameters below surgical thresholds. Modern imaging techniques (such as hybrid PET-CT and 4D flow MRI) afford the non-invasive assessment of anatomic, hemodynamic, and molecular features of the aorta, and may provide for a more accurate selection of patients who will benefit from preventative surgical intervention. In the current review, we summarize evidence and considerations regarding predictive aortic imaging and highlight evolving imaging modalities that have shown promise to improve risk assessment for the occurrence of dissection and rupture.

Key Points

- Guidelines for the preventative management of aortic disease depend on maximal vessel diameters, while these have shown to be poor predictors for the occurrence of catastrophic acute aortic events.

- Evolving imaging modalities (such as 4D flow MRI and hybrid PET-CT) afford a more comprehensive insight into anatomic, hemodynamic, and molecular features of the aorta and have shown promise to detect vessel wall instability at an early stage.
\end{abstract}

Keywords Aorta $\cdot$ Aortic dissection · Aortic aneurysm $\cdot$ Type A dissection $\cdot$ Aortic rupture

$\begin{array}{ll}\text { Abbreviations } \\ \text { AAA } & \text { Abdominal aortic aneurysm } \\ \text { AAS } & \text { Acute aortic syndrome } \\ \text { BAV } & \text { Bicuspid aortic valve } \\ \text { IMH } & \text { Intramural hematoma } \\ \text { PC } & \text { Phase contrast } \\ \text { SD } & \text { Standard deviation } \\ \text { TAA } & \text { Thoracic aortic aneurysm }\end{array}$

Bouke P. Adriaans

bouke.adriaans@mumc.nl

1 Department of Radiology and Nuclear Medicine, Maastricht University Medical Center+, P. Debyelaan 25, 6229

HX Maastricht, the Netherlands

2 Department of Cardiology, Maastricht University Medical Center+, Maastricht, the Netherlands

3 Cardiovascular Research Institute Maastricht (CARIM), Maastricht University, Maastricht, the Netherlands

4 Department of Radiology, Leiden University Medical Center, Leiden, the Netherlands
VSMC Vascular smooth muscle cell

WSS Wall shear stress

\section{Introduction}

\begin{abstract}
"Upon examining the heart, its pericardium was found distended with a quantity of coagulated blood, nearly sufficient to fill a pint cup; the whole heart was so compressed as to prevent any blood contained in the veins from being forced into the auricles; therefore, the ventricles were found absolutely void of blood; and, in the trunk of the aorta, we found a transverse fissure on its inner side, about an inch and a half long, through which some blood had recently passed ..."
\end{abstract}

In 1760, King George II of Great Britain died unexpectedly while "straining on the toilet," and so became subject of the first ever case report on acute type A aortic dissection [1]. At autopsy, the King's personal physician described findings of 
an intimal vessel wall tear and subsequent cardiac tamponade, which - as we now know - is one of the most feared complications of dissection. Along with pathophysiologically distinct entities like aneurysm rupture and intramural hematoma (IMH), dissection belongs to the spectrum of acute aortic syndromes (AASs). Despite best efforts, these have proven challenging to predict, and annual incidence rates have been stable at approximately 10 per 100,000 over the past decades [2, 3]. Cardiovascular imaging plays a central role in the preventative management of aortic disease, since guidelines traditionally depend on diameter criteria for stratification towards prophylactic surgical intervention $[4,5]$. In the current review, we summarize evidence and considerations regarding predictive aortic imaging and highlight modern imaging techniques that have shown promise to improve risk assessment for the occurrence of dissection and rupture.

\section{Best current practice-aortic diameters}

\section{Normal diameters}

The aorta is the largest artery in the body and runs from the aortic valve until the abdominal bifurcation. From proximal to distal, it consists of the aortic root, ascending aorta, aortic arch, descending thoracic aorta, and abdominal aorta (Fig. 1). Cross-sectional diameters are influenced by gender, patient habitus, and hypertension, and increase in an indolent manner by approximately $0.1 \mathrm{~mm} /$ year [6]. Reference values for the different anatomic segments have been established by multiple imaging modalities, including echocardiography, CT, and MRI [7-9]. Imaging guidelines provide specific measurement recommendations for each of these techniques and emphasize that there exists no standardized method across modalities [10]. Therefore, diameters can vary slightly depending on trigger time (end-systolic vs. end-diastolic) and edge selection (leading edge-to-leading edge vs. inner edge-inner edge vs. outer edge-outer edge). In general, it is stressed that measurements should be performed perpendicular to the aortic centerline (i.e., on double oblique images), and that measurement location and methodology should be specified in order to provide for accurate follow-up in individuals with an indication for repetitive imaging [11-13].

\section{Thoracic aortic aneurysm}

An aneurysm is defined as a localized arterial dilatation of $\geq 2$ standard deviations (SDs) above the expected vessel diameter [14]. The underlying pathophysiological mechanisms differ partially for aneurysms at various locations along the aorta. Whereas thoracic aortic aneurysm (TAA) results from excessive degeneration of the medial layer of the vessel wall (also known as cystic medial necrosis), the formation of abdominal

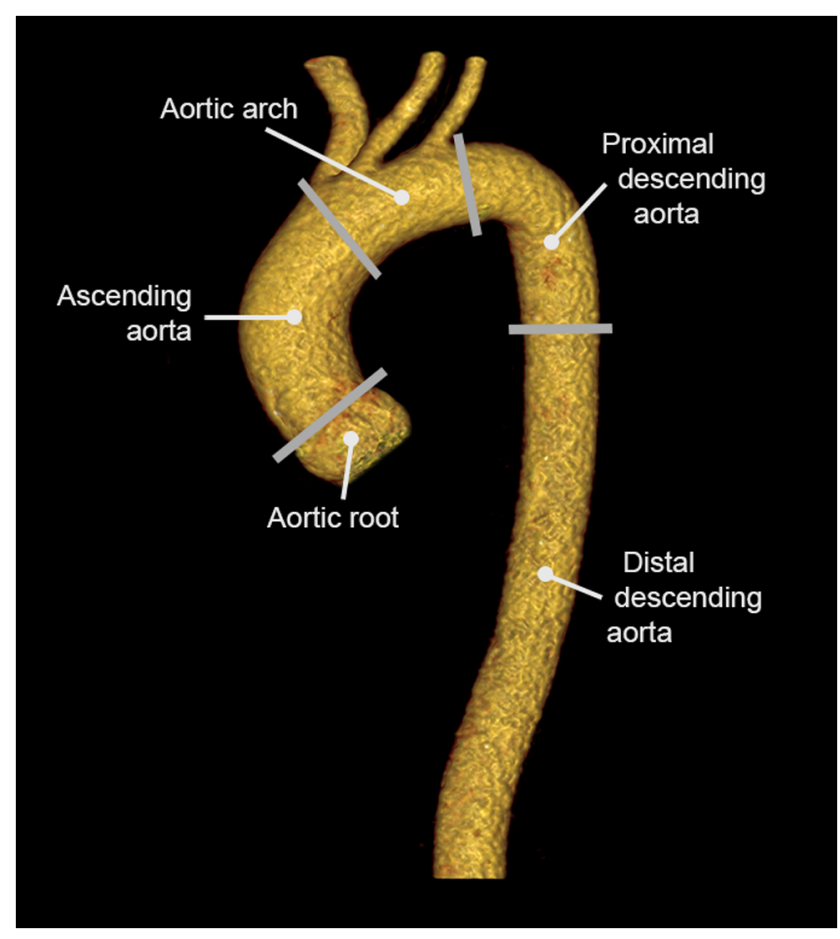

Fig. 1 Three-dimensional CT reconstruction of a healthy thoracic aorta. The ascending aorta runs from the sinotubular junction until the first branch vessel (brachiocephalic trunk), while the aortic arch is defined as the segment that contains the three branch vessels. The descending thoracic aorta is divided into two parts: a proximal part (from the left subclavian artery to the level of the pulmonary artery) and a distal part (from the pulmonary artery to the diaphragm)

aortic aneurysms (AAAs) is mainly associated with atherosclerosis [15]. However, the net result - extensive remodeling of the extracellular matrix of the vessel wall with loss of vascular smooth muscle cells (VSMCs) and elastin content-is similar for all aneurysms [15].

Progressive aortic dilatation is a well-acknowledged risk factor for the occurrence of both acute dissection and rupture. While these natural complications are rare in ascending aortic aneurysms of moderate size (yearly rupture or dissection risk of $0.08 \%, 0.22 \%$, and $0.58 \%$ at diameters of 45,50 , and $55 \mathrm{~mm}$, respectively), a sharp step-up in their occurrence - to $6.9 \%$ yearly-is observed when the diameter exceeds $60 \mathrm{~mm}$ (Fig. 2) [16-18]. In descending thoracic aneurysms, a similar "hinge point" is identified at $70 \mathrm{~mm}$ [18]. In order to avoid aneurysm expansion beyond these critical points, the general consensus is to refer patients for pre-emptive surgery at $55 \mathrm{~mm}$ (ascending aorta) or 55 to $60 \mathrm{~mm}$ (descending thoracic aorta, depending on the eligibility for an endovascular approach) [4, 5, 19]. More frequent surveillance imaging and lower surgical cut-offs apply to patients with connective tissue diseases (such as Marfan syndrome), who are at increased risk for negative outcomes [5]. In these patients, surgery is indicated at diameters $\geq 50 \mathrm{~mm}$, or even $\geq 45 \mathrm{~mm}$ in the copresence of additional risk factors (growth rate $>3$ 
Fig. 2 Lifetime probability of dissection or rupture at various sizes of the thoracic aorta. Note the "hinge points" at $6 \mathrm{~cm}$ (ascending aorta) and $7 \mathrm{~cm}$ (descending thoracic aorta), at which the natural complication risk suddenly escalates. Reprinted from Elefteriades et al, $J \mathrm{Am}$ Coll Cardiol 2010;55(9):841-857, with permission from Elsevier
Ascending aorta

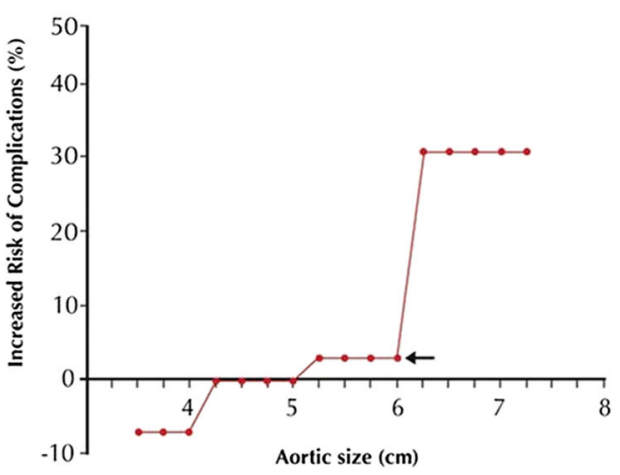

Descending aorta

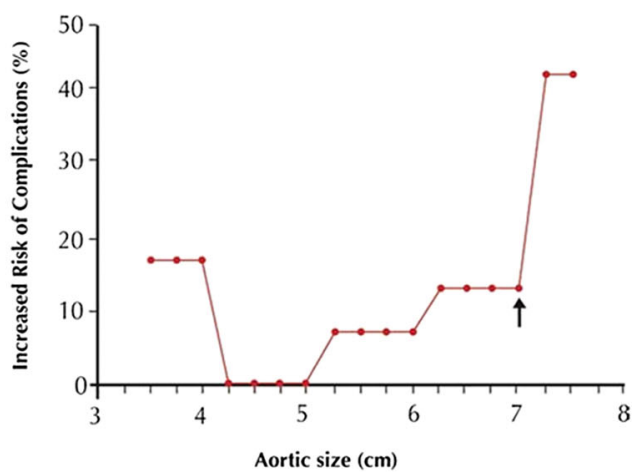

$\mathrm{mm}$ /year, familial history of dissection, or severe valvular regurgitation). Patients with bicuspid aortic valve (BAV) and concomitant risk factors are also considered for surgery at a lower than normal threshold ( $\geq 50 \mathrm{~mm}$ ), although evidence for this approach is lacking [4, 5, 20]. Admittedly, BAV is overrepresented in large dissection cohorts, but the higher number of aortic events in this patient group cannot be seen independent from its increased TAA prevalence $[17,21]$. At any given TAA diameter, the yearly aortic complication risk for bicuspid and tricuspid valves has shown to be comparable [22].

\section{Aortic size paradox}

Despite the evident link between TAA formation and unfavorable outcomes, the vast majority of dissections occur in aortas with diameters below the threshold for preventative surgery-the so-called aortic size paradox. Retrospective studies have shown that only $30-41 \%$ of patients with type A and $18 \%$ of patients with type B dissection had diameters $\geq 5.5 \mathrm{~cm}$ at the time of presentation [23-26]. Since the aorta dilates by about one-third of its size directly after dissection onset, the number of events that could have been prevented by current diameter cutoffs is probably even lower [27-29]. Nevertheless, it is questionable if lowering the thresholds for surgical intervention would bear a long-term mortality benefit. Given the large population at risk, it would more likely expose a considerable number of patients with smaller TAAs - and thus, minimal yearly risk of natural complications - to the $3.7-8.3 \%$ mortality risk associated with elective surgery [30]. In conclusion, it could be stated that the aortic diameter predicts rupture and dissection on a populational level, but is an insufficient parameter to identify individuals at risk. For this reason, recent research interests have shifted to the deciphering of additional risk factors for AAS, in an attempt to enhance personalized risk assessment and clinical decision-making.

\section{Modern perspectives-moving beyond diameters}

\section{Aortic elongation and volume}

One drawback of maximal diameter measurements is that they do not adequately represent the three-dimensional process of aortic growth. Aneurysm lengthening and cylindrical deformation are two scenarios of positive remodeling that are not necessarily accompanied by an increase of maximal diameters [31]. Since more advanced acquisition and post-processing techniques are required to assess the three-dimensional geometry of the aorta, data on its length and volume are relatively scarce. Similar to its diameters, normal aortic length has shown to increase with age $[32,33]$. With the vessel being confined within the thoracic cavity, this lengthening process naturally causes the artery to become more tortuous [32]. Driven by observations that the intimal entry tear runs in the transverse direction in the majority of cases (i.e., results from disruptive stretch in the longitudinal direction), recent studies have investigated the role of excessive elongation in the pathophysiology of dissection $[34,35]$. They found that increased vessel curvature significantly elevates the forces acting on the aortic wall and that vessel length serves as an independent risk factor for the occurrence of both type A and type B dissection (Fig. 3) [36-39].

To date, the added value of volume measurements in the management of thoracic aortic disease is not fully understood. Several AAA studies have suggested improved sensitivity for detection of aneurysm growth by reporting that substantial volume expansion can occur even while the maximal diameter remains stable [40-43]. This finding is important, since it implicates (rapid) growth in regions proximally or distally from the widest portion of the aneurysm sac. Volumetry has also shown improved intra- and inter-observer variability when compared with diameter measurements, which is another argument in favor of its use in clinical aneurysm follow-up [44]. Although no causal link with adverse outcomes has yet been established, the 


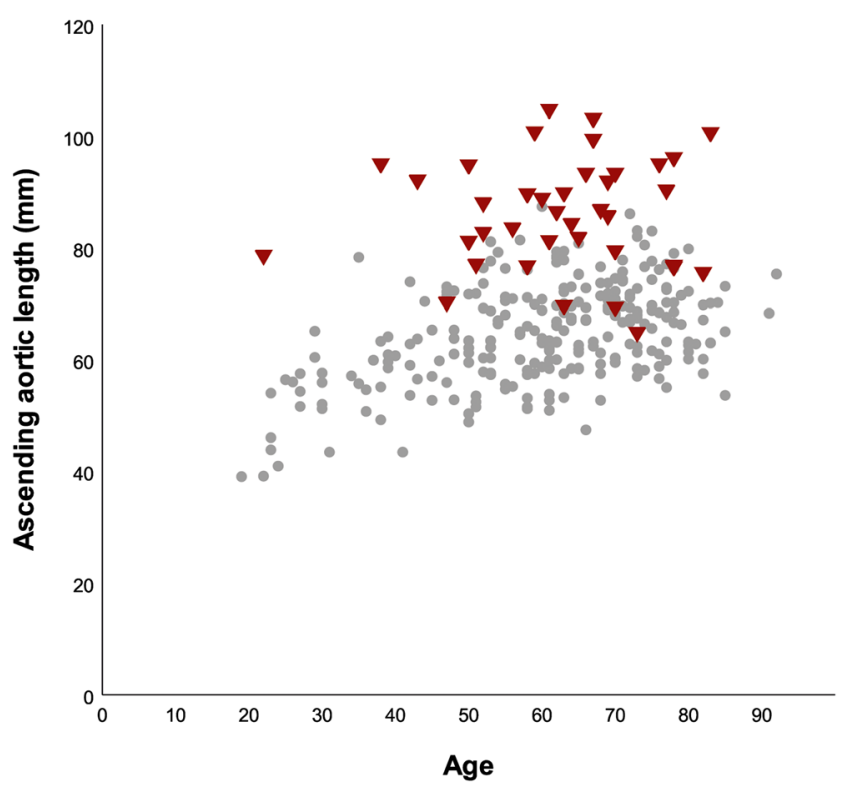

Fig. 3 Scatter plot depicting the length of the ascending aorta in patients with acute type A dissection (red) and healthy controls (gray). In the majority of dissection patients, the aorta was evidently lengthened (mean difference of $2.0 \mathrm{~cm}$ when compared with propensity-matched healthy controls). Adapted by permission from BMJ Publishing Group Limited, from Heuts et al, Aortic elongation part II: the risk of acute type A aortic dissection, Heart 2018;104:1778-1782

cited studies have demonstrated that aortic length and volume can be measured on routinely obtained CT using commercially available software packages. This widespread availability makes them feasible predictive parameters for use in a clinical setting, although longitudinal — and, preferably, prospective - studies are now required as the next step in their validation process.

\section{Aortic hemodynamics}

The role of hemodynamics in the pathogenesis of aortopathy has been subject of a long-standing debate. Especially in BAV patients, who exhibit enlarged aortic diameters even in the absence of valvular dysfunction, there has been controversy regarding the origin of aneurysm formation [45]. Two theories explain the accelerated aortic growth rates and high prevalence of TAA in this patient group: (i) a genetic theory, which rests on evidence that BAV is a congenital condition with considerable genetic heterogeneity and (ii) a hemodynamic theory, in which abnormal flow patterns and turbulence cause elevated wall stress and subsequent vessel remodeling [46]. Several genes (such as NOTCH1, ACTA2, and GATA5) have been associated with abnormal development of the aortic valve $[46,47]$. Given that the aortic cusps and the medial layer of the ascending aorta are embryologically linked (i.e., both originate from the neural crest), it is conceivable that the genes responsible for BAV formation can also affect the development of the aortic vessel wall. Other arguments in support of the genetic theory include observations that BAV aortopathy is not uncommon in children and adolescents, and that progressive diameter increase can occur even after replacement of the aortic valve [48, 49]. Initially, the histologic presence of cystic medial necrosis was also presented as an argument for disease inheritability, as this was believed to resemble findings in those with Marfan syndrome [50]. However, later work has demonstrated that medial degeneration is a common feature of all TAAs and dissected aortas, regardless of their underlying etiology $[15,51]$.

Over the past few years, the hemodynamic theory has become increasingly popular, along with the evolvement of
Fig. 4 a Streamline visualization of a BAV patient, showing a pronounced eccentric and helical flow pattern. $\mathbf{b}$ The adjacent WSS map showing elevated wall stress in the greater curvature of the aorta, at the location of impingement between the eccentric jet and the vessel wall

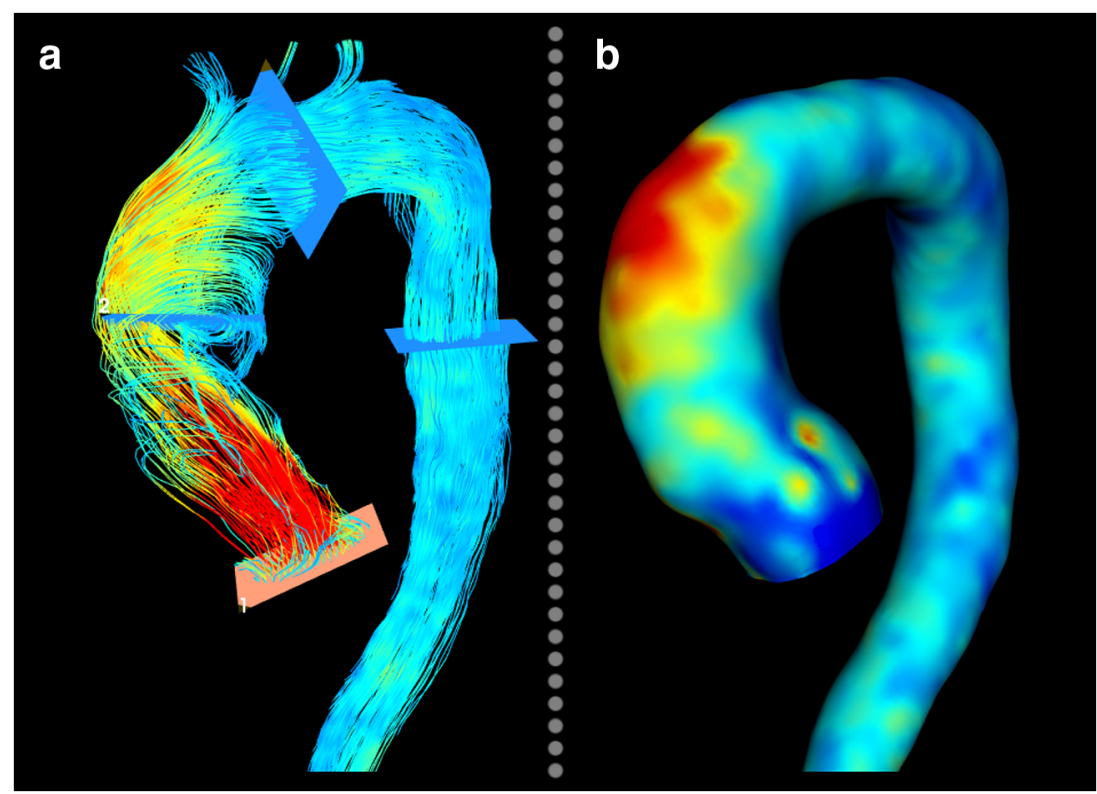


functional imaging modalities that afford a more comprehensive insight into aortic hemodynamics. In flow MRI, phasecontrast (PC) techniques are used to generate image contrast between moving protons (such as in blood) and stationary protons (most soft tissues). The underlying concept is based on the feature of protons to accumulate an MRI phase shift that is proportional to the speed at which they move along a magnetic gradient field. Phase-contrast MRI is traditionally performed using a manually positioned two-dimensional (2D) acquisition that encodes velocity in one principal direction. This approach generates time-resolved velocity maps, which can be used to quantify flow rates and velocities of blood moving through the imaging slice. As such, it enables evaluation of a broad spectrum of cardiovascular diseases, including assessment of shunt fractions and valvular regurgitant volumes. Over recent years, methodological advances have facilitated the acquisition of time-resolved, three-dimensional, three-directionally encoded velocity data. This technique, commonly known as 4D flow MRI, affords a uniquely detailed flow visualization within the heart and large vessels and allows post hoc flow quantification at any location within an acquired volume [52]. Furthermore, the obtained velocity data can be used for estimation of various flowderived hemodynamic parameters, including wall shear stress (WSS) and normalized flow displacement. In BAV patients, 4D flow MRI has revealed markedly eccentric and helical
Normal WSS (0)

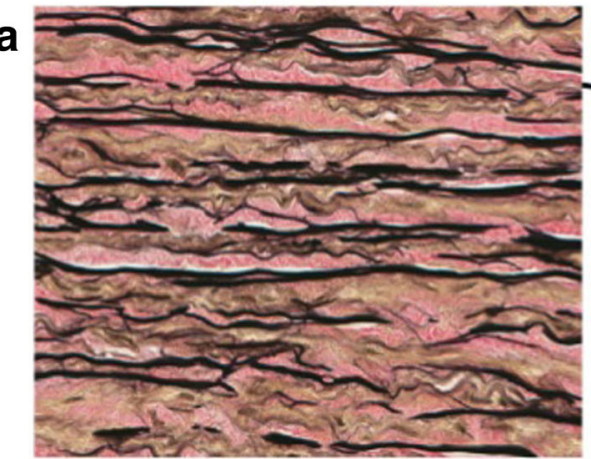

b

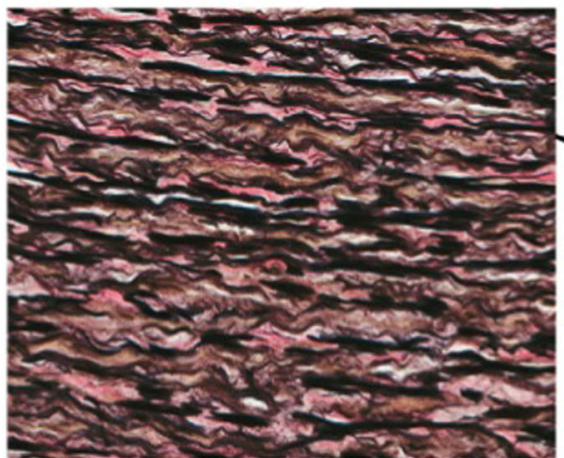

C

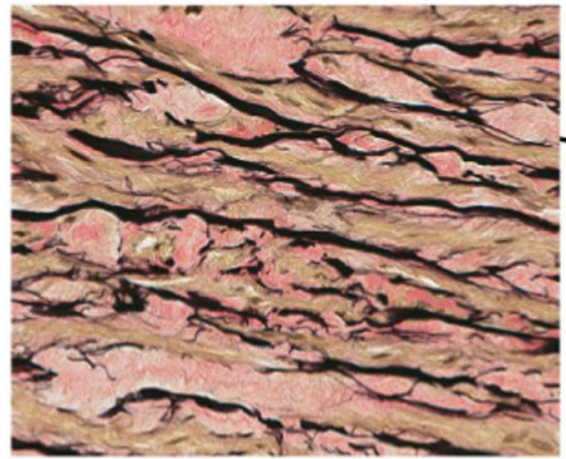

3D WSS Heatmaps

left-anterior view right-posterior view
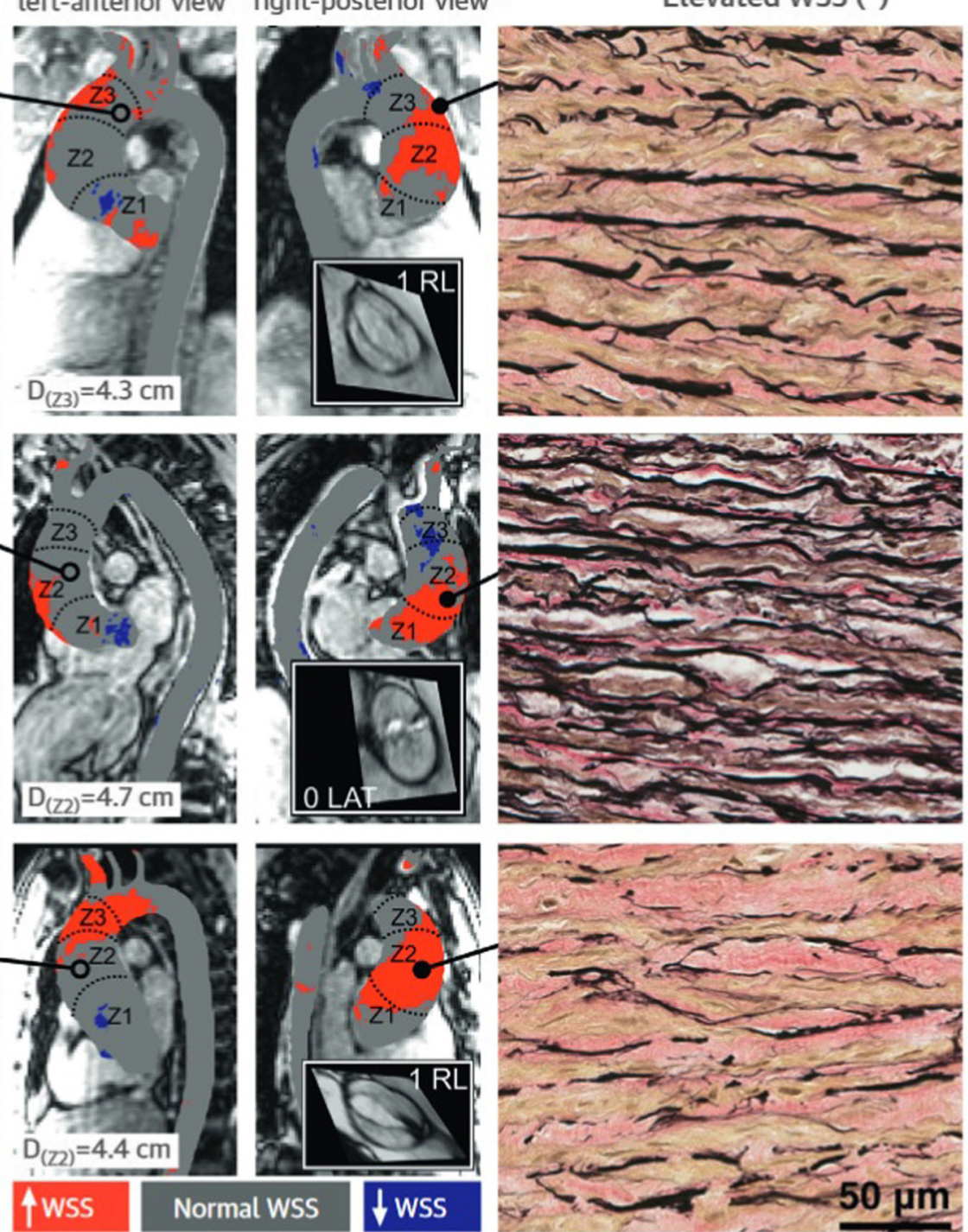

Fig. 5 Aortic wall specimens of regions with normal WSS (left panels) and high WSS (right panels) in three (a-c) patients with BAV aortopathy ( $\times 40$ magnification). Note the decreased number of elastin fibers (black) in the context of elevated WSS. Center panel: 4D flow MRI-based maps depicting areas with increased (red) and depressed (blue) WSS. Reprinted from Guzzardi et al, Valve-related hemodynamics mediate human bicuspid aortopahy, J Am Coll Cardiol 2015;66:892-900, with permission from Elsevier 
flow with highest flow velocities and WSS located along the aortic vessel wall (Fig. 4) [53, 54]. For each BAV cusp fusion type, a typical WSS distribution pattern with elevated shear stress at the location of impingement between the flow jet and vessel wall was identified [55]. Subsequently, raphe-specific WSS patterns have shown to correspond with the phenotype of BAV aortopathy (i.e., left-right coronary cusp fusion leads to sole dilatation of the tubular ascending aorta, whereas a raphe between the right- and non-coronary cusps causes more diffuse dilatation with involvement of the aortic root, tubular ascending aorta, and aortic arch) $[56,57]$. In a recent contribution, Guzzardi et al have also demonstrated a more direct association between WSS and histologic changes of the aortic vessel wall [58]. In their study, BAV patients who were scheduled for ascending aortic replacement underwent preoperative WSS mapping. During surgery, paired tissue samples of aortic regions with normal and elevated WSS were collected to show that increased WSS was associated with dysregulation of the extracellular matrix and degeneration of elastin fibers (Fig. 5).

Flow displacement is another 4D flow MRI parameter that has shown potential to predict progression of aortic disease. It provides a quantitative measure of flow eccentricity by calculating the distance between the location of peak systolic flow and vessel center in a 2D imaging plane [59]. Like WSS, the degree and direction of flow displacement depend on the underlying aortic valve phenotype [56]. As yet, it is the only 4D flow MRI parameter that has been associated with aortic growth in a (small) longitudinal cohort study. In this study (mean follow-up duration, over 4 years), BAV patients with eccentric aortic flow exhibited faster diameter growth than those with laminar flow profiles $(1.2 \mathrm{~mm} /$ year vs. $0.3 \mathrm{~mm} /$ year, respectively) [60]. Larger longitudinal studies that aim to acquire the clinical relevance of various 4D flow MRI parameters are currently ongoing.

\section{Vessel wall inflammation}

Immunohistochemical studies have reported extensive inflammatory activity within the aneurysmatic vessel wall [15].
Whereas the presence of lymphocytes and activated macrophages is rare in a healthy aorta, elevated numbers of $\mathrm{CD}^{+}$ and $\mathrm{CD} 68^{+}$cells were found throughout the medial layer of TAAs [51]. Of note, infiltration of these cells has shown to be even more pronounced in the dissected aorta, raising the question whether the degree of inflammation can be used to discriminate between low- and high-risk patients [51]. Since leukocytes demand glucose for their accelerated metabolic processes, areas of increased inflammatory activity can be detected using positron emission tomography (PET). This imaging modality depends on measurements of radioactivity emitted after administration of a radioactive tracer, most commonly the glucose derivative 18-fluoro-2-deoxyglucose (FDG; $>95 \%$ of all PET examinations). FDG is transported into cells by glucose transporters and becomes phosphorylated to form FDG-6-phosphate. Unlike glucose-6-phosphate, FDG-6phosphate is not further metabolized along the glycolytic pathway and becomes trapped within the cell in a concentration that is in proportion to that cells' glucose consumption. In animal experiments, FDG avidity has shown to be positively correlated with macrophage content of the arterial vessel wall $[61,62]$. A similar association has been observed in vivo in patients with abdominal aneurysms $[63,64]$. Furthermore, the AAA study by Reeps et al reported FDG uptake to be associated with a decrease in collagen content and VSMCs-factors that determine the stability of the aortic wall. However, despite these promising results, studies that sought to investigate the use of FDG-PET for prediction of AAA expansion and rupture have reported conflicting results. Whereas two prospective studies have demonstrated elevated tracer uptake to be associated with disease progression, others could not establish such a relationship [65-70]. As yet, only one study has investigated the use of PET-CT in thoracic aortic disease. In a small sample of hemodynamically stable patients with various acute aortic conditions (e.g., type B dissection, penetrating ulcer, or IMH), this longitudinal study showed increased FDG uptake to be associated with the risk of disease progression (Fig. 6) [71]. Of the 11 included patients with increased FDG uptake, nine $(82 \%)$ showed progression of wall pathology under conservative treatment requiring emergency medical

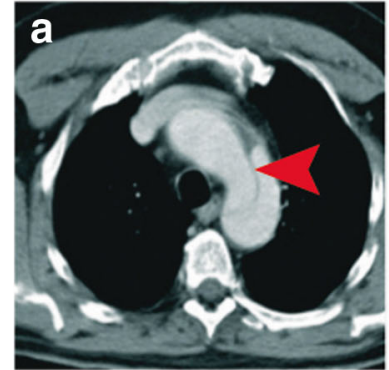

b

Fig. 6 a Contrast-enhanced CT depicting type B dissection (arrowhead) in a patient with acute chest pain. b, $\mathbf{c}$ Adjacent PET and PET-CT examinations revealed regions of elevated FDG uptake in the dissected

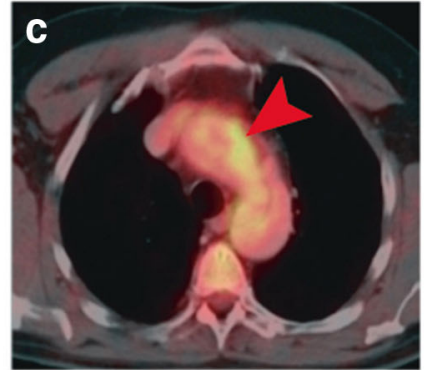

vessel wall (arrowheads). Adapted by permission from BMJ Publishing Group Limited, from Kuehl et al, Heart 2008;94:1472-1477 
intervention, and three of these nine patients died. In contrast, only 10 of the 22 (45\%) PET-negative patients experienced disease progression (two deaths).

In conclusion, no clear relation between FDG-PET and clinical outcomes in thoracic and abdominal aneurysm patients has yet been demonstrated, although it should be noted that the inconsistency between studies partly relates to their small and heterogeneous study populations. Prospective studies with larger patient cohorts are warranted to assess the actual clinical value of FDG-PET. Also, future work could address the clinical value of novel radiotracers that have shown potential to target other processes within the inflammatory pathway of aneurysmal disease, such as expression of matrix metalloproteases (MMPSense 680), active vascular calcification (18F-NaF), and chemokine receptor 4 expression (68-Gapentixafor) [72-74]. The recent integration of PET and MRI into PET/MRI scanners has afforded the synchronized evaluation of anatomic, physiologic, and molecular imaging features, and could serve as a promising imaging platform in the future.

\section{Conclusions}

Excessive aortic dilatation (diameter $\geq 5.5 \mathrm{~cm}$ ) poses a significant risk for the occurrence of acute aortic events, and patients with aneurysms beyond this size should be referred for prophylactic surgical intervention. However, the majority of acute aortic events occur in aortas with diameters below surgical thresholds. Therefore, these patients would not have qualified for preventative surgery, even when screened appropriately prior to event onset. Several modern imaging techniques (such as hybrid PET-CT and 4D flow MRI) have shown promise to detect vessel wall instability at an early stage. Studies that aim to demonstrate a causal link with the occurrence of acute aortic syndromes are currently ongoing and could lead to the integration of these techniques into clinical practice guidelines.

Funding This study has received funding from Stichting de Weijerhorst, Maastricht, Limburg, the Netherlands.

\section{Compliance with ethical standards}

Guarantor The scientific guarantor of this publication is prof. J.E. Wildberger.

Conflict of interest The authors of this manuscript declare no relationships with any companies, whose products or services may be related to the subject matter of the article.

Statistics and biometry No complex statistical methods were necessary for this paper.
Informed consent Written informed consent was not required for this review article.

Ethical approval Institutional Review Board approval was not required because this is a review article.

\section{Methodology}

- review

Open Access This article is distributed under the terms of the Creative Commons Attribution 4.0 International License (http:// creativecommons.org/licenses/by/4.0/), which permits unrestricted use, distribution, and reproduction in any medium, provided you give appropriate credit to the original author(s) and the source, provide a link to the Creative Commons license, and indicate if changes were made.

\section{References}

1. Nicholls F (1761) Observations concerning the body of His Late Majesty. Philos Trans 52:265-275

2. Howard DP, Banerjee A, Fairhead JF, Perkins J, Silver LE, Rothwell PM (2013) Population-based study of incidence and outcome of acute aortic dissection and pre-morbid risk-factor control: 10 -year results from the Oxford Vascular Study. Circulation 127(2): 2031-2037

3. Olsson C, Thelin S, Ståhle E, Ekbom A, Granath F (2006) Thoracic aortic aneurysm and dissection: increasing prevalence and improved outcomes reported in a nationwide population-based study of more than 14000 cases from 1987 to 2002. Circulation. 114(24): 2611-2618

4. Erbel R, Aboyans V, Boileau C et al (2014) 2014 ESC guidelines on the diagnosis and treatment of aortic diseases: Document covering acute and chronic aortic diseases of the thoracic and abdominal aorta of the adult. The Task Force for the Diagnosis and Treatment of Aortic Diseases of the European Society of Cardiology (ESC). Eur Heart J 35(41):2873-2926

5. Hiratzka LF, Bakris GL, Beckman JA et al (2010) 2010 ACCF/ AHA/AATS/ACR/ASA/SCA/SCAI/SIR/STS/SVM Guidelines for the diagnosis and management of patients with thoracic aortic disease. A Report of the American College of Cardiology Foundation/American Heart Association Task Force on Practice Guidelines, American Association for Thoracic Surgery, American College of Radiology,American Stroke Association, Society of Cardiovascular Anesthesiologists, Society for Cardiovascular Angiography and Interventions, Society of Interventional Radiology, Society of Thoracic Surgeons, and Society for Vascular Medicine. J Am Coll Cardiol 55(14):e27-e129

6. Roman MJ, Devereux RB, Kramer-Fox R, O’Loughlin J (1989) Two-dimensional echocardiographic aortic root dimensions in normal children and adults. Am J Cardiol 64(8):507-512

7. Burman ED, Keegan J, Kilner PJ (2008) Aortic root measurement by cardiovascular magnetic resonance: specification of planes and lines of measurement and corresponding normal values. Circ Cardiovasc Imaging 1(2):104-113

8. Wolak A, Gransar H, Thomson LE et al (2008) Aortic size assessment by noncontrast cardiac computed tomography: normal limits by age, gender, and body surface area. JACC Cardiovasc Imaging 1(2):200 209

9. Hager A, Kaemmerer H, Rapp-Bernhardt U et al (2002) Diameters of the thoracic aorta throughout life as measured with helical computed tomography. J Thorac Cardiovasc Surg 123(6):1060-1066 
10. Goldstein SA, Evangelista A, Abbara S et al (2015) Multimodality imaging of diseases of the thoracic aorta in adults: from the American Society of Echocardiography and the European Association of Cardiovascular Imaging: endorsed by the Society of Cardiovascular Computed Tomography and Society for Cardiovascular Magnetic Resonance. J Am Soc Echocardiogr 28(2):119-182

11. Bireley WR 2nd, Diniz LO, Groves EM, Dill K, Carroll TJ, Carr JC (2007) Orthogonal measurement of thoracic aorta luminal diameter using ECG-gated high-resolution contrast-enhanced MR angiography. J Magn Reson Imaging 26(6):1480-1485

12. Mendoza DD, Kochar M, Devereux RB et al (2011) Impact of image analysis methodology on diagnostic and surgical classification of patients with thoracic aortic aneurysms. Ann Thorac Surg 92(3):904-912

13. Rudarakanchana N, Bicknell C, Cheshire N et al (2014) Variation in maximum diameter measurements of descending thoracic aortic aneurysms using unformatted planes versus images corrected to aortic centerline. Eur J Vasc Endovasc Surg 47(1):19-26

14. Goldfinger JZ, Halperin JL, Marin ML, Stewart AS, Eagle KA, Fuster V (2014) Thoracic aortic aneurysm and dissection. J Am Coll Cardiol 64(16):1725-1739

15. Guo DC, Papke CL, He R, Milewicz DM (2006) Pathogenesis of thoracic and abdominal aortic aneurysms. Ann N Y Acad Sci 1085(1):339-352

16. Davies RR, Goldstein LJ, Coady MA et al (2002) Yearly rupture or dissection rates for thoracic aortic aneurysms: simple prediction based on size. Ann Thorac Surg 73(1):17-28

17. Kim JB, Spotnitz M, Lindsay ME, MacGillivray TE, Isselbacher EM, Sundt TM 3rd (2016) Risk of aortic dissection in the moderately dilated ascending aorta. J Am Coll Cardiol 68(11):1209-1219

18. Elefteriades JA, Farkas EA (2010) Thoracic aortic aneurysm: clinically pertinent controversies and uncertainties. J Am Coll Cardiol 55(9):841-857

19. Riambau V, Böckler D, Brunkwall J et al (2017) Management of descending thoracic aorta diseases: clinical practice guidelines of the European Society for Vascular Surgery (ESVS). Eur J Vasc Endovasc Surg 53(1):4-52

20. Nishimura RA, Otto CM, Bonow RO et al (2014) 2014 AHA/ACC guideline for the management of patients with valvular heart disease: a report of the American College of Cardiology/American Heart Association Task Force on Practice Guidelines. J Am Coll Cardiol 63(22):e57-e185

21. Michelena HI, Khanna AD, Mahoney D et al (2011) Incidence of aortic complications in patients with bicuspid aortic valves. JAMA. 306(10):1104-1112

22. Davies RR, Kaple RK, Mandapati D et al (2007) Natural history of ascending aortic aneurysms in the setting of an unreplaced bicuspid aortic valve. Ann Thorac Surg 83(4):1338-1344

23. Parish LM, Gorman JH 3rd, Kahn S et al (2009) Aortic size in acute type A dissection: implications for preventive ascending aortic replacement. Eur J Cardiothorac Surg 35(6):941-946

24. Kim EK, Choi SH, Sung K et al (2014) Aortic diameter predicts acute type A aortic dissection in patients with Marfan syndrome but not in patients without Marfan syndrome. J Thorac Cardiovasc Surg 147(5):1505-1510

25. Pape LA, Tsai TT, Isselbacher EM et al (2007) Aortic diameter $\geq$ $5.5 \mathrm{~cm}$ is not a good predictor of type A aortic dissection observations from the International Registry of Acute Aortic Dissection (IRAD). Circulation. 116(10):1120-1127

26. Trimarchi S, Jonker FH, Hutchison S et al (2011) Descending aortic diameter of $5.5 \mathrm{~cm}$ or greater is not an accurate predictor of acute type B aortic dissection. J Thorac Cardiovasc Surg 142(3):e101-e107

27. Rylski B, Blanke P, Beyersdorf F et al (2014) How does the ascending aorta geometry change when it dissects? J Am Coll Cardiol 63(13):1311-1319
28. Rylski B, Branchetti E, Bavaria JE et al (2014) Modeling of predissection aortic size in acute type A dissection: more than $90 \%$ fail to meet the guidelines for elective ascending replacement. J Thorac Cardiovasc Surg 148(3):944-948 e1

29. Mansour AM, Peterss S, Zafar MA et al (2018) Prevention of aortic dissection suggests a diameter shift to a lower aortic size threshold for intervention. Cardiology. 139(3):139-146

30. Gazoni LM, Speir AM, Kron IL, Fonner E, Crosby IK (2010) Elective thoracic aortic aneurysm surgery: better outcomes from high-volume centers. J Am Coll Surg 210(5):855-859

31. Martufi G, Auer M, Roy J et al (2013) Multidimensional growth measurements of abdominal aortic aneurysms. J Vasc Surg 58(3): 748-755

32. Adriaans BP, Heuts S, Gerretsen S et al (2018) Aortic elongation part I: the normal aortic ageing process. Heart. 104(21):1772-1777

33. Sugawara J, Hayashi K, Yokoi T, Tanaka H (2008) Age-associated elongation of the ascending aorta in adults. JACC Cardiovasc Imaging 1(6):739-748

34. O'Rourke M, Farnsworth A, O'Rourke J (2008) Aortic dimensions and stiffness in normal adults. J Am Coll Cardiol Img 1(6):749-751

35. Hirst AE Jr, Johns VJ Jr, Kime SW Jr (1958) Dissecting aneurysm of the aorta: a review of 505 cases. Medicine (Baltimore). 37(3): 217-279

36. Poullis MP, Warwick R, Oo A, Poole RJ (2008) Ascending aortic curvature as an independent risk factor for type A dissection, and ascending aortic aneurysm formation: a mathematical model. Eur J Cardiothorac Surg 33(6):995-1001

37. Heuts S, Adriaans BP, Gerretsen S et al (2018) Aortic elongation part II: the risk of acute type A aortic dissection. Heart. 104(21): $1778-1782$

38. Krüger T, Oikonomou A, Schibilsky D et al (2017) Aortic elongation and the risk for dissection: the Tübingen Aortic Pathoanatomy (TAIPAN) Project. Eur J Cardiothorac Surg 51(6):1119-1126

39. Lescan M, Veseli K, Oikonomou A et al (2017) Aortic elongation and Stanford B dissection: the Tübingen Aortic Pathoanatomy (TAIPAN) Project. Eur J Vasc Endovasc Surg 54(2):164-169

40. Renapurkar RD, Setser RM, O'Donnell TP et al (2012) Aortic volume as an indicator of disease progression in patients with untreated infrarenal abdominal aneurysm. Eur J Radiol 81(2):e87-e93

41. Kauffmann C, Tang A, Therasse É et al (2012) Measurements and detection of abdominal aortic aneurysm growth: accuracy and reproducibility of a segmentation software. Eur J Radiol 81(8):1688-1694

42. Lindquist Liljeqvist M, Hultgren R, Gasser TC, Roy J (2016) Volume growth of abdominal aortic aneurysms correlates with baseline volume and increasing finite element analysis-derived rupture risk. J Vasc Surg 63(6):1434-1442 e3

43. den Hartog AW, Franken R, de Witte P et al (2013) Aortic disease in patients with Marfan syndrome: aortic volume assessment for surveillance. Radiology. 269(2):370-377

44. Trinh B, Dubin I, Rahman O et al (2017) Aortic volumetry at contrast-enhanced MR angiography: feasibility as a sensitive method for monitoring bicuspid aortic valve aortopathy. Invest Radiol 52(4):216

45. Della Corte A, Bancone C, Quarto C et al (2007) Predictors of ascending aortic dilatation with bicuspid aortic valve: a wide spectrum of disease expression. Eur J Cardiothorac Surg 31(3):397-405

46. Siu SC, Silversides CK (2010) Bicuspid aortic valve disease. J Am Coll Cardiol 55(25):2789-2800

47. Garg V, Muth AN, Ransom JF et al (2005) Mutations in NOTCH1 cause aortic valve disease. Nature. 437(7056):270

48. Gurvitz M, Chang RK, Drant S, Allada V (2004) Frequency of aortic root dilation in children with a bicuspid aortic valve. Am J Cardiol 94(10):1337-1340

49. Yasuda H, Nakatani S, Stugaard M et al (2003) Failure to prevent progressive dilation of ascending aorta by aortic valve replacement 
in patients with bicuspid aortic valve: comparison with tricuspid aortic valve. Circulation. 108(10 suppl 1):II-291-II-4

50. Nataatmadja M, West M, West J et al (2003) Abnormal extracellular matrix protein transport associated with increased apoptosis of vascular smooth muscle cells in Marfan syndrome and bicuspid aortic valve thoracic aortic aneurysm. Circulation. 108(10 suppl 1):II329-II-34

51. He R, Guo DC, Estrera AL et al (2006) Characterization of the inflammatory and apoptotic cells in the aortas of patients with ascending thoracic aortic aneurysms and dissections. J Thorac Cardiovasc Surg 131(3):671-678

52. Markl M, Frydrychowicz A, Kozerke S, Hope M, Wieben O (2012) 4D flow MRI. J Magn Reson Imaging 36(5):1015-1036

53. Barker AJ, Markl M, Bürk J et al (2012) Bicuspid aortic valve is associated with altered wall shear stress in the ascending aorta. Circ Cardiovasc Imaging 5(4):457-466

54. Hope MD, Hope TA, Crook SE et al (2011) 4D flow CMR in assessment of valve-related ascending aortic disease. JACC Cardiovasc Imaging 4(7):781-787

55. Bissell MM, Hess AT, Biasiolli L et al (2013) Aortic dilation in bicuspid aortic valve disease: flow pattern is a major contributor and differs with valve fusion type. Circ Cardiovasc Imaging 6(4): 499-507

56. Mahadevia R, Barker AJ, Schnell S et al (2014) Bicuspid aortic cusp fusion morphology alters aortic three-dimensional outflow patterns, wall shear stress, and expression of aortopathy. Circulation. 129(6):673-682

57. Kang JW, Song HG, Yang DH et al (2013) Association between bicuspid aortic valve phenotype and patterns of valvular dysfunction and bicuspid aortopathy: comprehensive evaluation using MDCT and echocardiography. JACC Cardiovasc Imaging 6(2):150-161

58. Guzzardi DG, Barker AJ, Van Ooij P et al (2015) Valve-related hemodynamics mediate human bicuspid aortopathy: insights from wall shear stress mapping. J Am Coll Cardiol 66(8):892-900

59. Sigovan M, Hope MD, Dyverfeldt P, Saloner D (2011) Comparison of four-dimensional flow parameters for quantification of flow eccentricity in the ascending aorta. J Magn Reson Imaging 34(5): $1226-1230$

60. Hope MD, Sigovan M, Wrenn SJ, Saloner D, Dyverfeldt P (2014) MRI hemodynamic markers of progressive bicuspid aortic valverelated aortic disease. J Magn Reson Imaging 40(1):140-145

61. Tawakol A, Migrino RQ, Hoffmann U et al (2005) Noninvasive in vivo measurement of vascular inflammation with F-18 fluorodeoxyglucose positron emission tomography. J Nucl Cardiol 12(3):294-301

62. Hyafil F, Cornily J-C, Rudd JH, Machac J, Feldman LJ, Fayad ZA (2009) Quantification of inflammation within rabbit atherosclerotic plaques using the macrophage-specific CT contrast agent N1177: a comparison with 18F-FDG PET/CT and histology. J Nucl Med 50(6):947-953

63. Reeps C, Essler M, Pelisek J, Seidl S, Eckstein HH, Krause BJ (2008) Increased 18F-fluorodeoxyglucose uptake in abdominal aortic aneurysms in positron emission/computed tomography is associated with inflammation, aortic wall instability, and acute symptoms. J Vasc Surg 48(2):417-423

64. Courtois A, Nusgens BV, Hustinx R et al (2013) 18F-FDG uptake assessed by PET/CT in abdominal aortic aneurysms is associated with cellular and molecular alterations prefacing wall deterioration and rupture. J Nucl Med 54(10):1740-1747

65. Nchimi A, Cheramy-Bien JP, Gasser TC et al (2014) Multifactorial relationship between $18 \mathrm{~F}$-fluoro-deoxy-glucose positron emission tomography signaling and biomechanical properties in unruptured aortic aneurysms. Circ Cardiovasc Imaging 7(1):82-91

66. Sakalihasan N, Van Damme H, Gomez P et al (2002) Positron emission tomography (PET) evaluation of abdominal aortic aneurysm (AAA). Eur J Vasc Endovasc Surg 23(5):431-436

67. Kotze CW, Groves AM, Menezes LJ et al (2011) What is the relationship between (1)(8)F-FDG aortic aneurysm uptake on PET/CT and future growth rate? Eur J Nucl Med Mol Imaging 38(8):14931499

68. Barwick TD, Lyons OT, Mikhaeel NG, Waltham M, O'Doherty MJ (2014) 18F-FDG PET-CT uptake is a feature of both normal diameter and aneurysmal aortic wall and is not related to aneurysm size. Eur J Nucl Med Mol Imaging 41(12):2310-2318

69. Morel O, Mandry D, Micard E et al (2015) Evidence of cyclic changes in the metabolism of abdominal aortic aneurysms during growth phases: (1)(8)F-FDG PET sequential observational study. J Nucl Med 56(7):1030-1035

70. Jalalzadeh H, Indrakusuma R, Planken RN, Legemate DA, Koelemay MJ, Balm R (2016) Inflammation as a predictor of abdominal aortic aneurysm growth and rupture: a systematic review of imaging biomarkers. Eur J Vasc Endovasc Surg 52(3):333-342

71. Kuehl H, Eggebrecht H, Boes T et al (2008) Detection of inflammation in patients with acute aortic syndrome: comparison of FDGPET/CT imaging and serological markers of inflammation. Heart. 94(11):1472-1477

72. Forsythe RO, Dweck MR, McBride OMB et al (2018) (18)FSodium fluoride uptake in abdominal aortic aneurysms: the SoFIA(3) Study. J Am Coll Cardiol 71(5):513-523

73. Michineau S, Franck G, Wagner-Ballon O, Dai J, Allaire E, Gervais M (2014) Chemokine (C-X-C motif) receptor 4 blockade by AMD3100 inhibits experimental abdominal aortic aneurysm expansion through anti-inflammatory effects. Arterioscler Thromb Vasc Biol 34(8):1747-1755

74. Kaijzel EL, van Heijningen PM, Wielopolski PA et al (2010) Multimodality imaging reveals a gradual increase in matrix metalloproteinase activity at aneurysmal lesions in live fibulin-4 mice. Circ Cardiovasc Imaging 3(5):567-577

Publisher's note Springer Nature remains neutral with regard to jurisdictional claims in published maps and institutional affiliations. 